\title{
Comparative Study on Solar Collector's Configuration for an Ejector-Refrigeration Cycle
}

\author{
Raffles Senjaya \& I Made Astina \\ Energy Conversion Research Division \\ Faculty of Mechanical and Aerospace Engineering \\ Institut Teknologi Bandung \\ Jalan Ganesha no 10 Bandung 40132, West Java, Indonesia \\ E-mail: astina@soon.com
}

\begin{abstract}
Solar collector's configuration plays important role on solar-powered refrigeration systems to work as heat source for generator. Three types of solar collector consisting of flat plate, evacuated tube, and compound parabolic solar collectors are compared to investigate their performances. The performances consist of the behavior of heat which can be absorbed by the collectors, heat loss from the collectors and outlet temperature of working fluid at several slopes of the solar collectors. The new accurate analysis method of heat transfer is conducted to predict the performance of the solar collectors. The analysis is based on several assumptions, i.e. sky condition at Bandung is clear and not raining from 08.00 until 17.00 and thermal resistance at cover and absorber plate is negligible. The numerical calculation results confirm that performance of the evacuated tubes solar collector at the same operating conditions is higher than the others. For the case of an evacuated-tubes solar collector system with aperture area of $3.5 \mathrm{~m}^{2}$, the maximum heat which can be absorbed is $3992 \mathrm{~W}$ for the highest solar intensity of $970 \mathrm{~W} / \mathrm{m}^{2}$ at 12.00 with horizontal position of the solar collector. At this condition, the highest outlet temperature of water is $347.15 \mathrm{~K}$ with mass flow rate $0.02 \mathrm{~kg} / \mathrm{s}$ and inlet temperature $298 \mathrm{~K}$.
\end{abstract}

Keywords: ejector refrigeration cycle; solar-powered refrigeration system; solar collector.

\section{$1 \quad$ Introduction}

The ejector refrigeration cycle can be used for cooling and heating systems. It is very attractive implementation as it provides an opportunity to utilize available low quality waste heat or the solar thermal energy $[1,2]$. Solar energy is one of the renewable energy which have several advantages, i.e. very abundant, free, and environment friendly. The solar collector is used to absorb heat from sun radiation and change it to be thermal energy as increasing of collector's working fluid temperature. Heat from the working fluid is transferred to refrigerant in an ejector-refrigeration cycle through generator. Solar energy absorbed by solar collector affects on variation of the water temperature from solar collector, and 
effectiveness of heat exchanger to transfer heat from hot water to refrigerant. Furthermore, the configuration of a solar collector plays important role to get the highest solar energy which can be absorbed by the collector with the least heat loss to the surrounding.

Most of this study investigates the thermal performance of three types of solar collectors by numerical method with the aim of choosing suitable solar collector type for the ejector-refrigeration system, as well as optimum operating condition for high efficiency. Evacuated tube, compound parabolic, and flatplate solar collectors are most widely used on the existing collector designs. Their performances are usually found to be more efficient for high solar intensity. On the other hand, evacuated tubes solar collector has its own set of advantages, including high efficiency and simple operation. The higher efficiency of evacuated tube solar collector is mainly due to the lower heat loss via the cover surface due to radiation and convection. Standard flat-plate solar collectors have typical efficiencies of $50 \%$ or less [3,4], while evacuated tube solar collectors have efficiencies of about $50-80 \%$ [5, 6]. It would be desirable to develop a new configuration for evacuated tubes collectors with higher efficiency, while its capital cost still remains low.

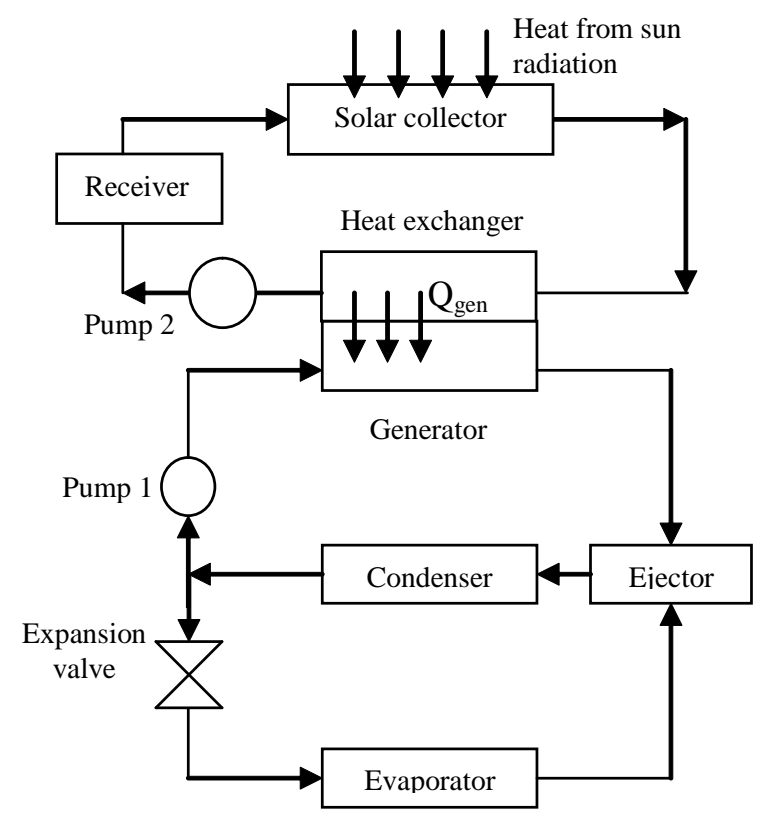

Figure 1 Schematic diagram of a simple ejector-refrigeration cycles with a solar collector. 
In this comparative study, the analysis of each type of solar collectors is only based on the thermal efficiency of the solar collectors and outlet temperature of water, which is influenced by outer surface temperature of the solar collector and their heat losses to environment. The solar collector is used to collect energy and restore it into water. Hot water supplies thermal energy for refrigerant in a generator. Schematic of the combine cycle is shown in Figure 1. On an ejector-refrigeration cycle powered by solar energy, there are two working fluids, one working fluid is refrigerant in the refrigeration cycle side, and the other working fluid is water at the solar collector side. Organic refrigerant may be chosen because it has a lower boiling temperature compared to water at the same pressure. The refrigerant should be included in non-ozone depletion substance group and it is possible to select non-global warming potential substance group. At pressure 1 bar and the highest solar intensity, water can reach temperature until $347 \mathrm{~K}$ with the inlet temperature $298 \mathrm{~K}$. At the average temperature of the water, refrigerant in the collector side will evaporate to be vapor. The vapor has higher thermal resistance compared to water. Choosing water as working fluid in the solar collector side is an effective way from heat transfer aspect.

\section{Solar Collector's Configuration}

Three types of solar collector are analyzed. They consist of flat plate (FPSC), evacuated tubes (ETSC), and compound parabolic solar collectors (CPSC). CPSC type is also called involute reflector solar collector (IRSC). View and dimension of each collector type are shown in Figure 2. The flat plate solar collector as shown in Figure 2.a is a simple solar collector that is available in the market. Most the products are made by local manufactures. The collector construction is composed as black-colored tubes and wrapping by opaque upper cover and metal sheet for other sides. Insulation material is also inserted in the metal sheets to reduce heat losses. Evacuated-tube solar collector as shown in Figure 2.b also rises in local markets. In the evacuated tube solar collector, the vacuum space is made inside the glass tubes, so that the manufacturing and assembly process is easier than other methods. Convective heat transfer can be neglected in the vacuum space. Therefore, this construction can reduce heat loss through convection. Other configuration of the solar collector as shown in Figure 2.c has more complex construction. Parabolic reflector is installed in opposite of incoming radiation of the sun. View of tube arrangement in each collector is shown in Figure 2.d. Distance of each tube is set at $50 \mathrm{~mm}$.

In order to conduct heat transfer analysis, the materials of the collectors are taken from available products at market. The main data needed as follows: 
1. Cover plate: sheet lime glass, refractive index of 1.5 , reflectivity of 0.08 , absorptivity of 0.03 , emissivity of 0.92 , and extinction coefficient of $4 / \mathrm{m}$.

2. Cover pipe: borosilicate glass type 33 , refractive index of 1.474 , vacuum space pressure of $0.005 \mathrm{~Pa}$, and thermal conductivity of $1.13 \mathrm{~W} / \mathrm{m} \cdot \mathrm{K}$.

3. Absorber plate: copper with black cobalt oxide coating, thermal conductivity of $385 \mathrm{~W} / \mathrm{m} \cdot \mathrm{K}$, and emissivity of 0.3 .

4. Insulation: fiber glass, thermal conductivity of $0.038 \mathrm{~W} / \mathrm{m} \cdot \mathrm{K}$, and emissivity of 0.07 .

5. Collector pipe: copper with ASTM B28 standard, size $3 / 4$ in (outlet diameter $19.05 \mathrm{~mm}$ ), 31 pipes, with separate $50 \mathrm{~mm}$ each other.

6. Reflector plate: aluminum polish, absorptivity of 0.09 , reflectivity of 0.91 , emissivity of 0.03 , and thermal conductivity of $168 \mathrm{~W} / \mathrm{m} \cdot \mathrm{K}$.

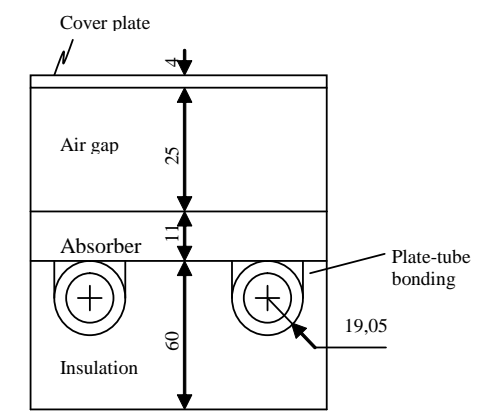

(a) Flat plate solar collector dimension

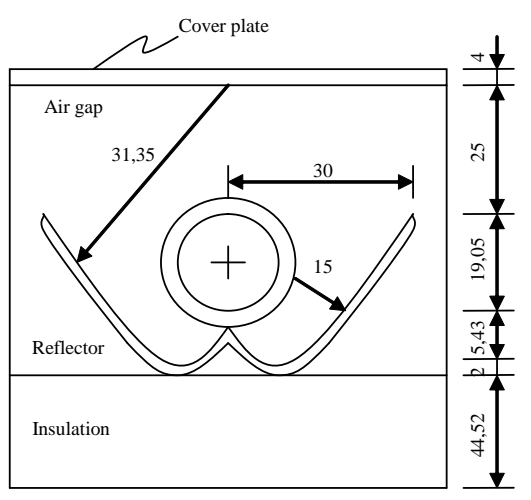

(c) Compound parabolic solar collector dimension

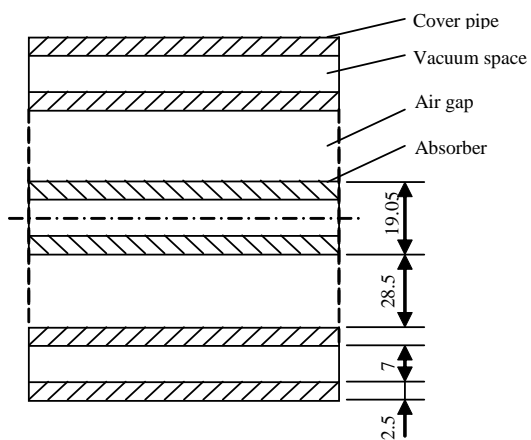

(b) Evacuated tubes solar collector dimension

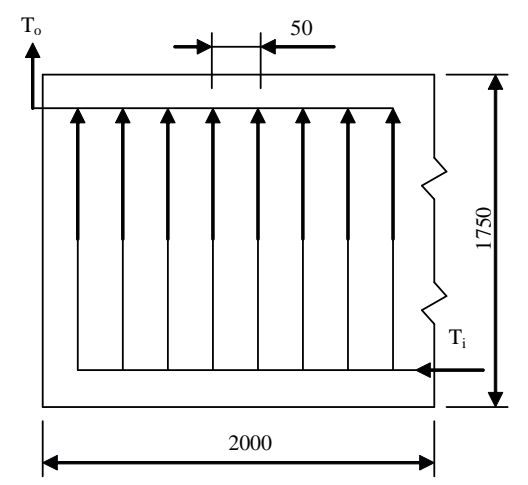

d) Solar collector's configuration at horizontal position (0 declivity)

Figure 2 Schematic dimension and configuration of solar collectors (unit in $\mathrm{mm})$. 


\section{$3 \quad$ Heat Transfer Analysis Method}

Accurate heat transfer analysis is needed to obtain reliable results. Radiation heat transfer is complex phenomena since it changes along time and depends on the solar position. The heat transfer analysis should be conducted in according with the sun radiation. For horizontal position, reflection occurs at a surface cover plate and different for every polarization components so that transmission and reflection radiation for every polarization components will be polarized. Using ray tracing techniques, the first non-polarized radiation will be transmitted. Transmissivity $(\tau)$, reflectivity $(\rho)$, and absorptivity $(\alpha)$ for single cover plate and non-polarized radiation can be obtained by calculating the average of perpendicular and parallel polarizations which defined by Eq. (1) from the ray tracing techniques are shown in Figure 3 [7].

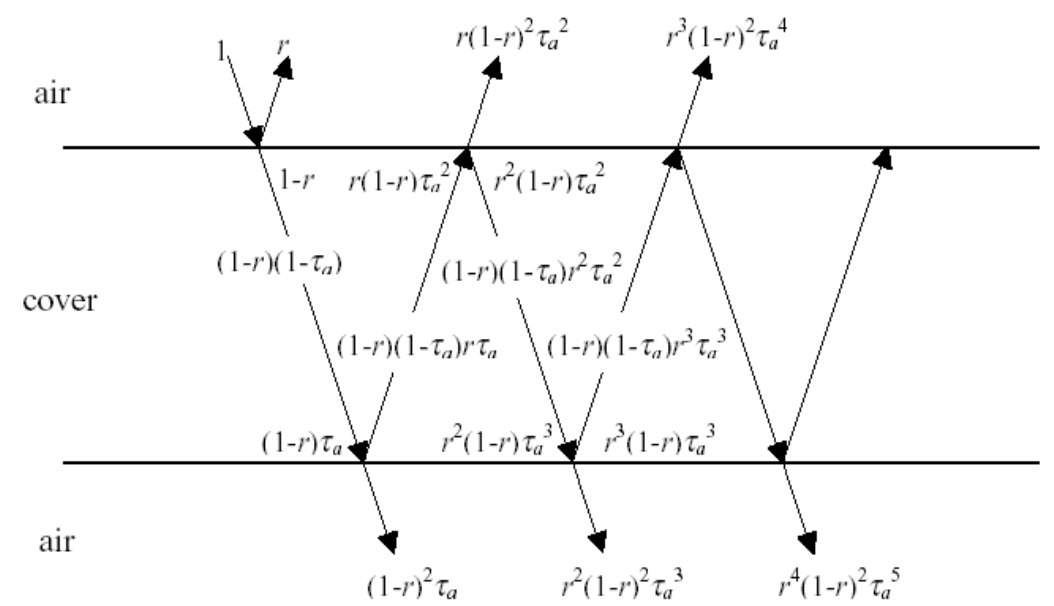

Figure 3 Ray tracing techniques for obtain transmissivity, reflectivity and absorptivity of single cover plate [7].

The averages of transmission, reflectivity and absorptivity are written as relation in Eq. (1).

$$
\tau=\frac{1}{2}\left(\tau_{\perp}+\tau_{\square}\right), \rho=\frac{1}{2}\left(\rho_{\perp}+\rho_{\square}\right), \alpha=\frac{1}{2}\left(\alpha_{\perp}+\alpha_{\square}\right)
$$

On the other hand, perpendicular and parallel components of polarization can be derived as final results given in Eq. (2.a) - (2.f). 


$$
\begin{gathered}
\tau_{\perp}=\tau_{a}(1-r)^{2} \sum_{n=0}^{\infty}\left(r \tau_{a}\right)^{2 n}=\frac{\tau_{a}\left(1-r_{\perp}\right)^{2}}{1-\left(r_{\perp} \tau_{a}\right)^{2}}=\tau_{a}\left(\frac{1-r_{\perp}}{1+r_{\perp}}\right)\left(\frac{1-r_{\perp}^{2}}{1-\left[r_{\perp} \tau_{a}\right]^{2}}\right) \quad(2 . \mathrm{a}) \\
\rho_{\perp}=r_{\perp}\left[1+\left(1-r_{\perp}\right)^{2} \tau_{a}^{2} \sum_{n=0}^{\infty}\left(r_{\perp} \tau_{a}\right)^{2 n}\right]=r_{\perp}\left[1+\frac{\left(1-r_{\perp}\right)^{2} \tau_{a}^{2}}{1-\left(r_{\perp} \tau_{a}\right)^{2}}\right]=r_{\perp}\left(1+\tau_{a} \tau_{\perp}\right) \\
\alpha_{\perp}=\left(1-\tau_{a}\right)\left(1-r_{\perp}\right) \sum_{n=0}^{\infty}\left(r_{\perp} \tau_{a}\right)^{n}=\frac{\left(1-\tau_{a}\right)\left(1-r_{\perp}\right)}{\left(1-\tau_{a} r_{\perp}\right)} \\
\tau_{\square}=\frac{\tau_{a}\left(1-r_{\square}\right)^{2}}{1-\left(r \tau_{a}\right)^{2}}=\tau_{a}\left(\frac{1-r_{\square}}{1+r_{\square}}\right)\left(\frac{1-r_{\square}^{2}}{1-\left[\tau_{a}\right]^{2}}\right) \\
\rho_{\square}=r_{\square}\left[1+\left(1-r_{\square}\right)^{2} \tau_{a}^{2} \sum_{n=0}^{\infty}\left(r \tau_{a}\right)^{2 n}\right]=r_{\square}\left[1+\frac{\left(1-r_{\square}\right)^{2} \tau_{a}^{2}}{1-\left(r_{\square} \tau_{a}\right)^{2}}\right]=r_{\square}\left(1+\tau_{a} \tau_{\square}\right) \\
\alpha_{\square}=\left(1-\tau_{a}\right)\left(1-r_{\square} \sum_{n=0}^{\infty}\left(r_{\square} \tau_{a}\right)^{n}=\frac{\left(1-\tau_{a}\right)\left(1-r_{\square}\right)}{\left(1-\tau_{a} r_{\square}\right)}\right.
\end{gathered}
$$

In evaluating performance of solar collector, $Q_{f}, T_{f, o}$, and $T_{c, a v g}$ are needed. Collector operation is assumed at steady state, so that heat which absorbed by collector is equal to heat which absorbed by working fluid. The heat transfer analysis is conducted by developing computer-program code using $\mathrm{C}++$ language programming to solve and iterate several equations of heat and mass transfer concurrently. The thermodynamic properties of the working fluid and air at $10^{5}$ and $0.005 \mathrm{~Pa}$ are obtained from the property calculation routine developed by REFPROP V8.0 [8, 9] and another researcher [10]. Absorbed heat by collector is defined by Eq. (3). 


$$
Q_{f}=Q_{a}-Q_{l}
$$

Absorbed heat by the collector is defined by Eq. (4).

$$
Q_{a}=\tau \alpha I A_{c}
$$

Heat loss from the collector to the surrounding is defined by Eq. (5).

$$
Q_{l}=U_{L} A_{c}\left(T_{c, a v g}-T_{a}\right)
$$

Outlet temperature of the water can be obtained by using Eq. (6).

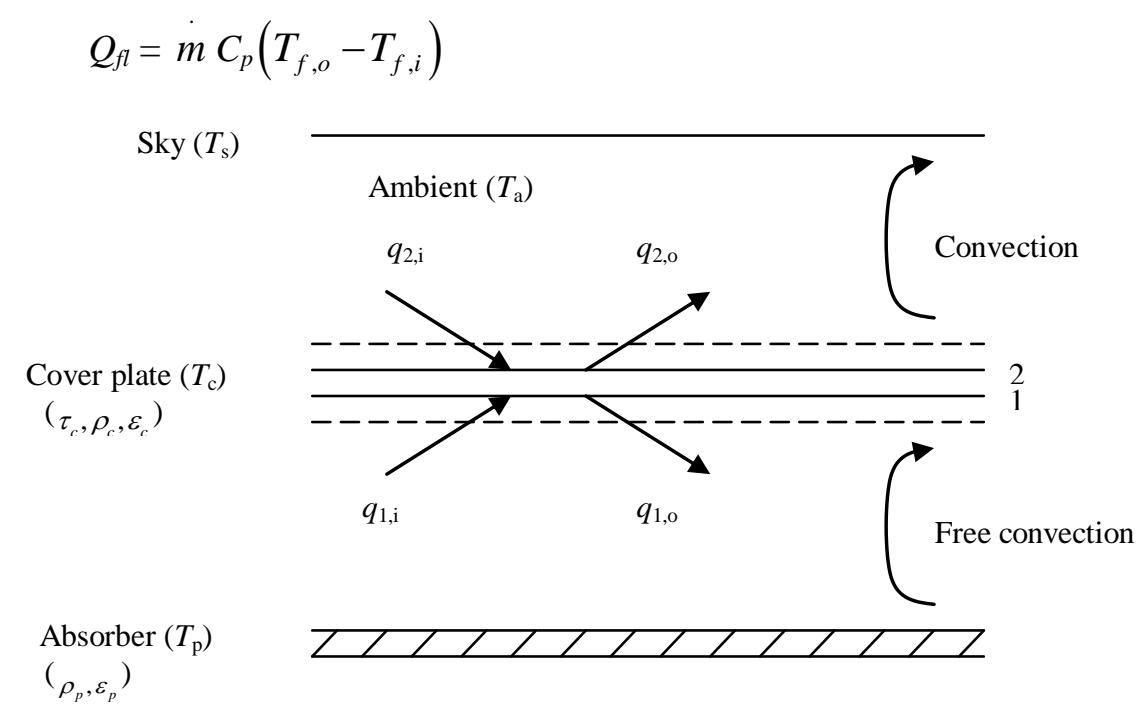

Figure 4 Heat transfer at single cover plate.

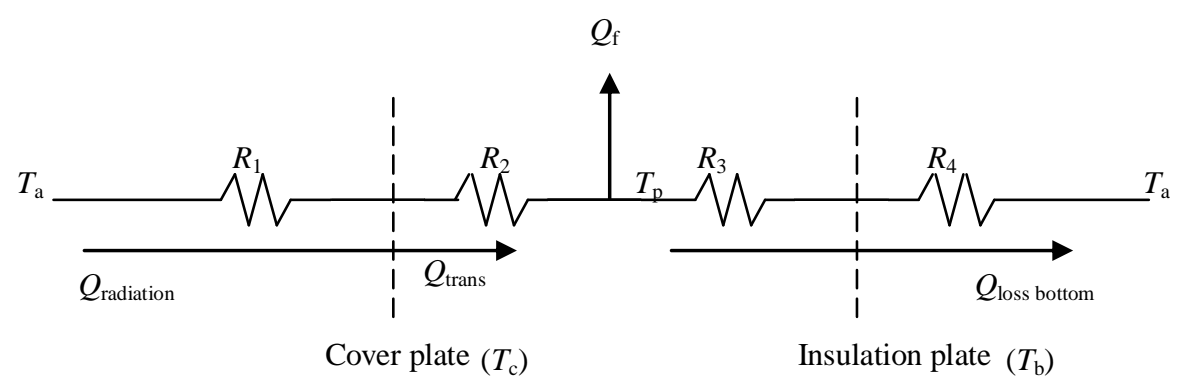

Figure 5 Thermal resistance of FPSC. 


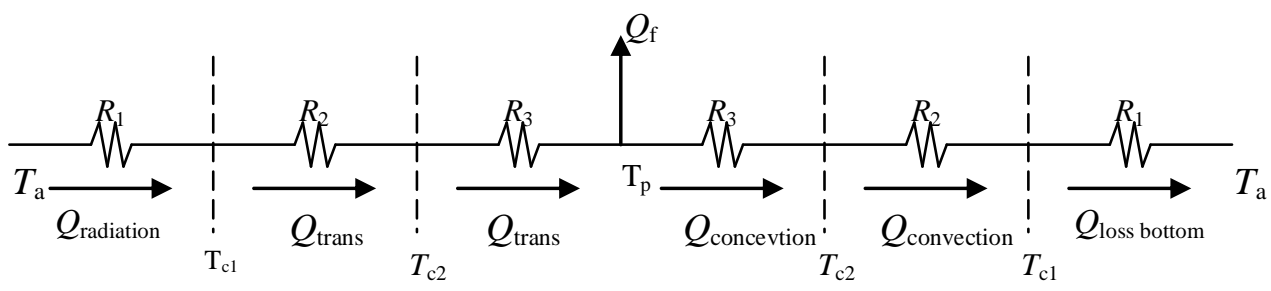

Figure 6 Thermal resistance of ETSC.

Heat transfer at top side of the solar collector with single cover plate is shown in Figure 4. Overall heat transfer coefficient can be obtained by calculating thermal resistance of each part of the solar collector. Thermal resistance arrangement of three types of the solar collectors is shown in Figures 5-7.

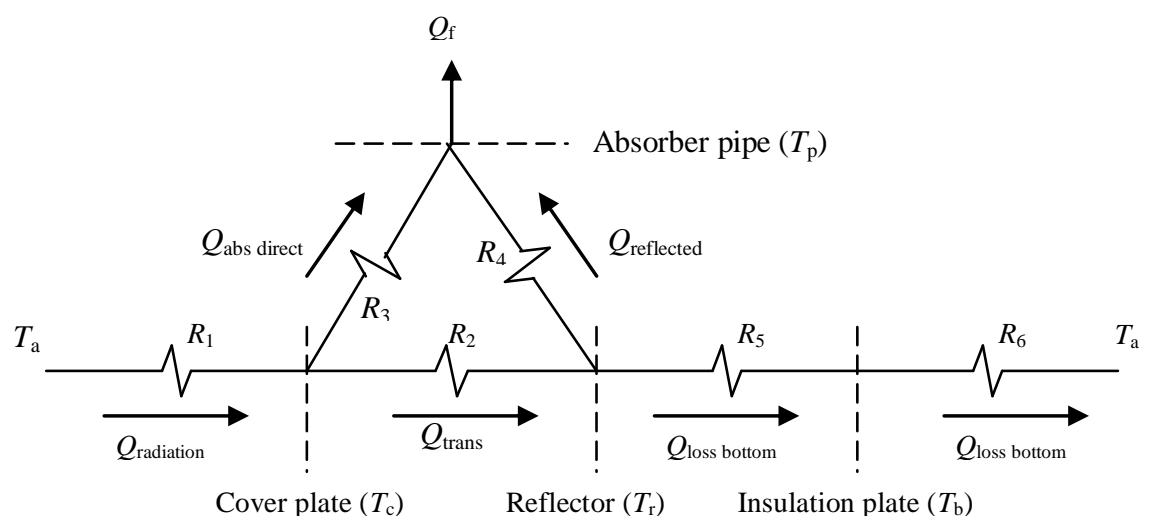

Figure 7 Thermal resistance of CPSC.

The thermal resistances are calculated with some assumptions. Cover and absorber plate do not have thermal resistance or temperature at two sides of plate is equal. At control volume of solar collector system, absorbed heat by collector is equal to heat loss from top, edge and bottom surface plus absorbed heat by working fluid. At ETSC, vacuum condition between inner and outer cover pipes make convection heat loss decrease significantly so that absorber pipe's temperature become higher and radiation heat transfer from absorber pipe to cover pipe increase. Radiation heat loss from absorber pipe to cover pipe is less than decreasing of convection heat transfer, so that the vacuum condition gives a significant improvement. At CPSC or IRSC, the profile of reflector is involute, same with gear's profile, so that all diffuse radiation from all direction will be reflected to absorber pipes without reflection radiation to surrounding. 
One half of absorber pipes at above side absorb heat directly and involute reflector is used to reflect the diffuse radiation to bottom side of absorber pipes.

The step calculation for analysis method is shown in Figure 8. Each type of solar collectors is calculated with input several parameters and properties and then guess the temperature of cover, absorber, and insulation plate first. The iteration is continued to calculate outlet temperature of working fluid with guess its value first. The final iteration is used to find absorber plate temperature. If it not equal with first guess value, the iteration will be repeated.

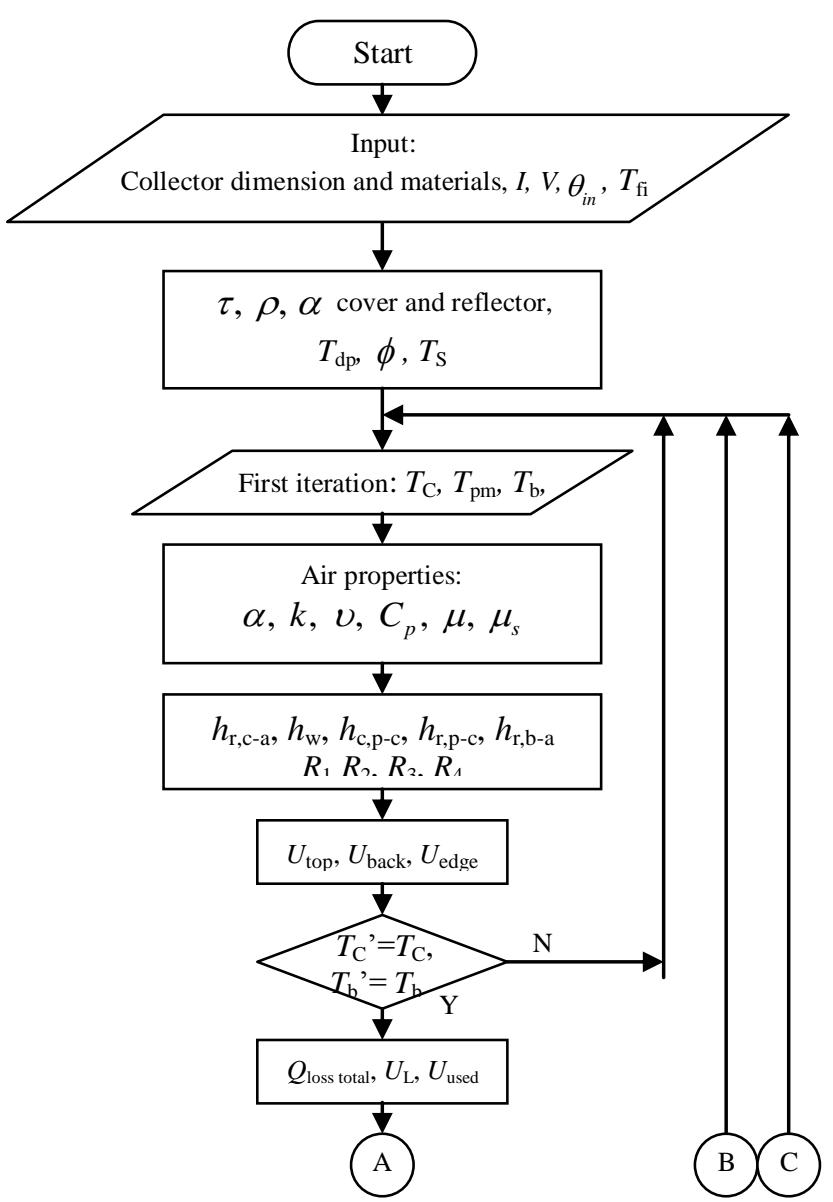

Figure 8 Flow chart of numerical calculation of solar collectors. 


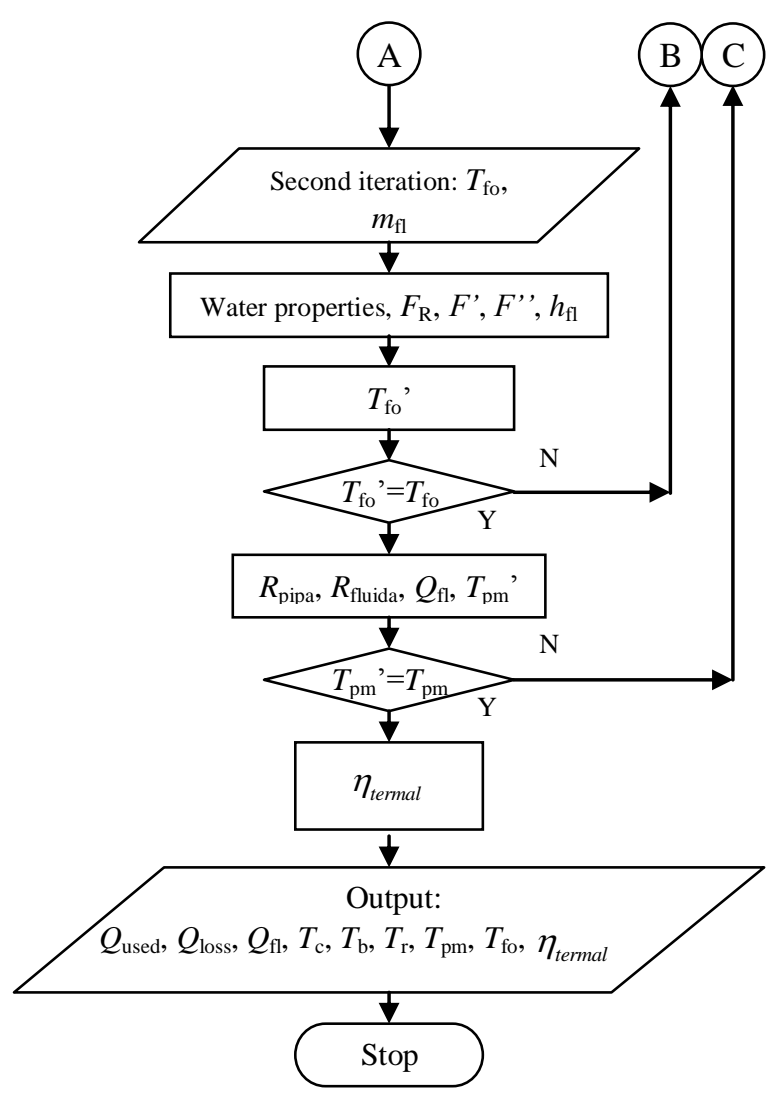

Figure 8 (continued).

\section{Calculation Result and Discussion}

Calculation results of this heat transfer analysis method bases of these assumptions are shown in Figures 9 and 10. Complexity of thermal resistance arrangement depends on the heat transfer modes involved and the collector configurations.

From these calculation results, evacuated tubes solar collector at 0 inclination shows the better performance than the others. At Figure 9 (a), ETSC can absorb heat more than the others because of the least heat loss, in Figure 9 (b). This condition causes ETSC reaching the maximum outlet temperature of working fluid. The maximum heat loss, occur at IRSC (CPC) because of the high reflector temperature so that heat loss from reflector to cover and insulation plate is also high. Efficiency is defined as absorbed heat by collector divided by radiation intensity at a specific time. For the same radiation intensity, solar 
collector efficiency in the evening is higher than in the morning because ambient temperature in the evening is higher than in the morning so that the difference temperature between cover and insulation plate to ambient in the evening smaller than in the morning. This condition makes lower heat loss from outer surfaces of solar collector to ambient.

The best inclination position of solar collector is 0 degree because at 0 degree the horizontal cross section area is highest, so that the maximum absorbed heat can be reached with maximum absorber area. 0 degree inclination of solar collector has disadvantages because system needs more power of pump to force the water flow at pipes. On the other side, with increasing inclination of solar collector, water can be reheated again because the higher temperature will go up due to the difference of density and the lower temperature will go down with gravitational force effect. It means that system can operate with natural convection (thermosyphon).

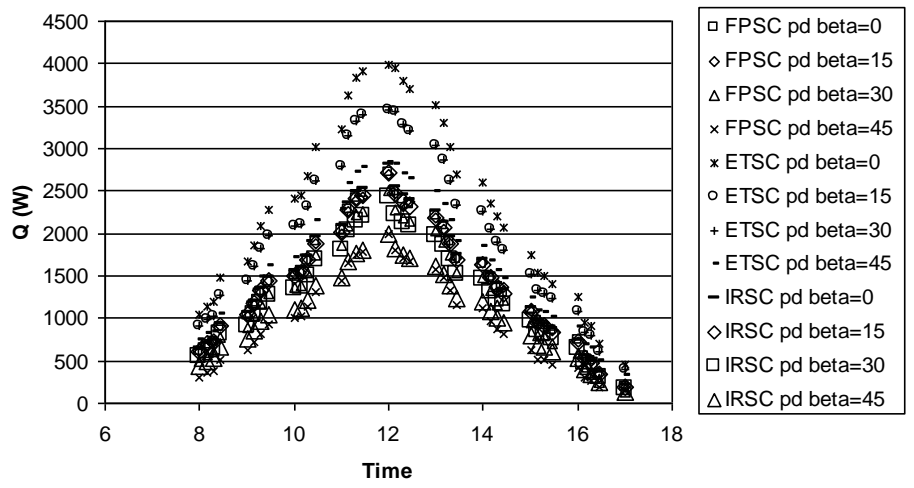

(a) Characteristics of absorbed heat by collector

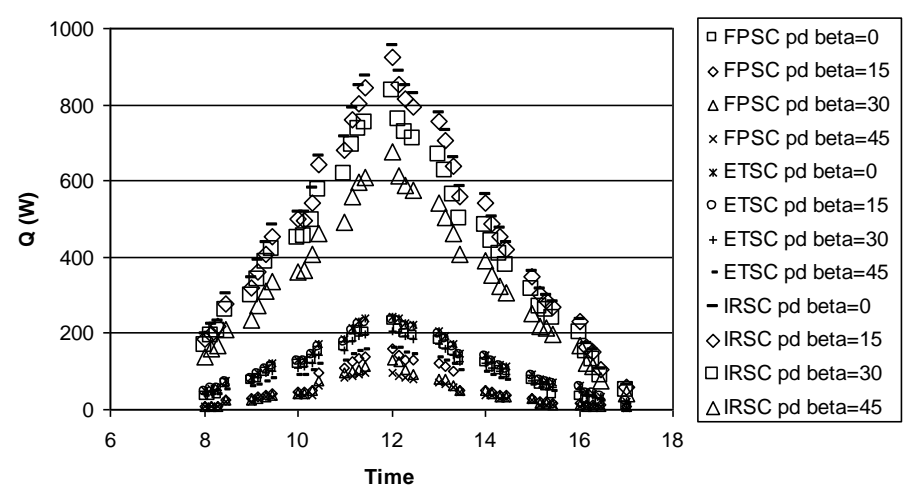

(b) Characteristics of heat loss

Figure 9 Numerical calculation result of solar collectors. 

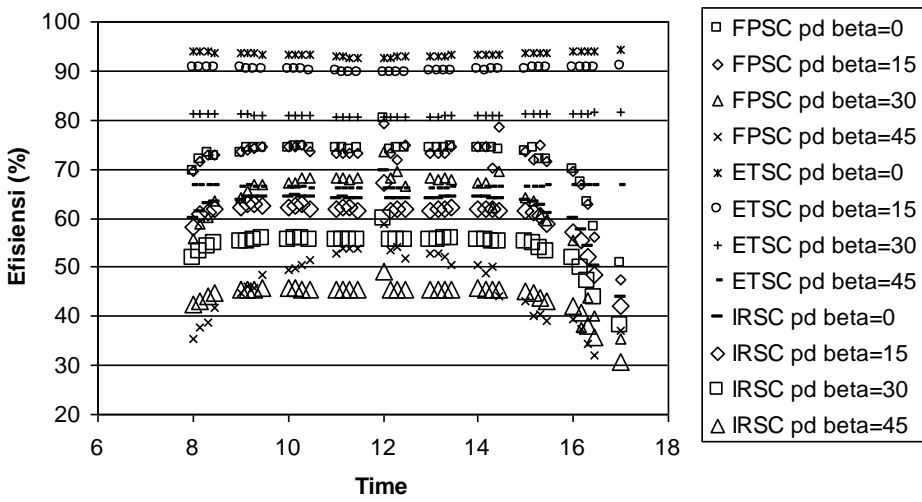

(c) Characteristics of efficiency

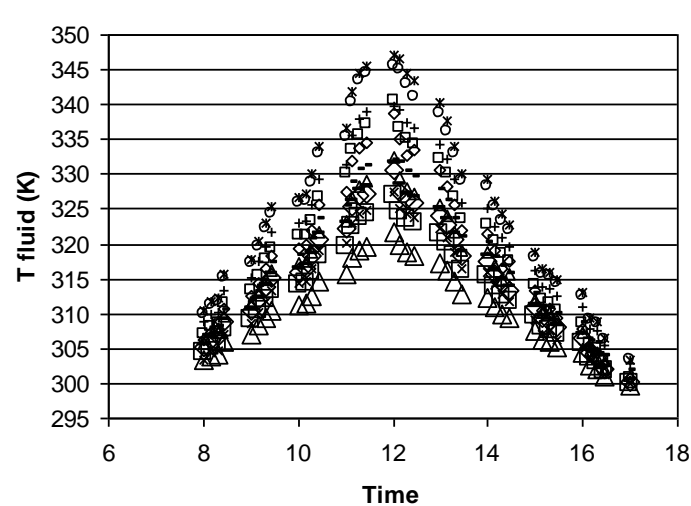

$\square$ FPSC pd beta $=0$ $\diamond$ FPSC pd beta $=15$ $\triangle$ FPSC pd beta $=30$ $\times$ FPSC pd beta $=45$ * ETSC pd beta $=0$ - ETSC pd beta $=15$ + ETSC pd beta $=30$ - ETSC pd beta $=45$ - IRSC pd beta $=0$ $\diamond$ IRSC pd beta $=15$ $\square$ IRSC pd beta $=30$ $\triangle \mathrm{IRSC}$ pd beta $=45$

(d) Characteristics of outlet temperature of working fluid

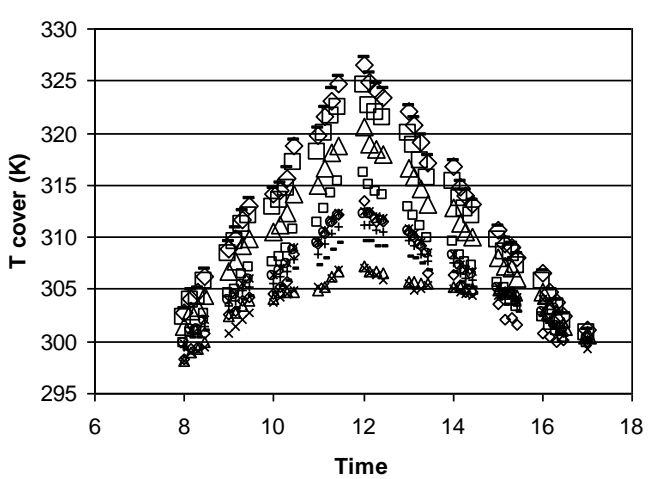
$\square$ FPSC pd beta $=0$
$\diamond$ FPSC pd beta $=15$
$\triangle$ FPSC pd beta $=30$
$\times$ FPSC pd beta $=45$
$*$ ETSC pd beta $=0$
- ETSC pd beta $=15$
+ ETSC pd beta $=30$
- ETSC pd beta $=45$
- IRSC pd beta $=0$
$\diamond$ IRSC pd beta $=15$
$\square$ IRSC pd beta $=30$
$\triangle I R S C$ pd beta $=45$

(e) Characteristics of cover plate temperature.

Figure 9 (continued). 


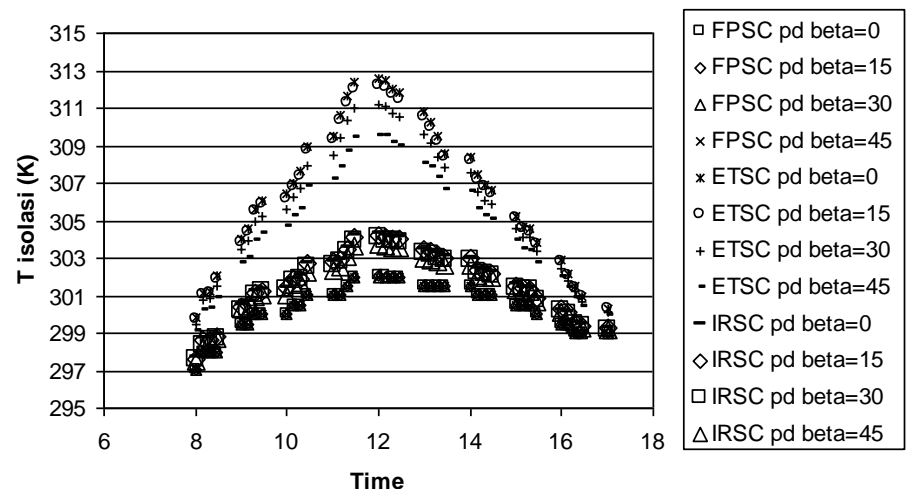

(f) Characteristics of bottom plate temperature

Figure 9 (continued).

To validate this new heat transfer calculation method, this method result is compared with experimental research. The experimental condition is different with this study condition especially at solar collector type and mass flow rate. It is based on absorb heat by collector per unity mass flow rate of working fluid. Available experimental data is the CPC 21 solar collector type (combine evacuate tubes with compound parabolic) with $3.5 \mathrm{~m}^{2}$ aperture area and 0.05 $\mathrm{kg} / \mathrm{s}$ mass flow rate. The comparison result is shown in Figure 10.

This comparison result was calculated with bases of real radiation intensity which obtained by radiation measurement with pyranometer on $26^{\text {th }}$ July 2006 in ITB Bandung. From Figure 10.a, at real condition with real intensity radiation measurement, in experimental research the maximum heat per unity of mass flow rate which can be absorbed by collector is $149.74 \mathrm{~kJ} / \mathrm{kg}$ compare to the calculation result is $200.45 \mathrm{~kJ} / \mathrm{kg}$ (ETSC), $126.73 \mathrm{~kJ} / \mathrm{kg}$ (FPSC), and 131.05 $\mathrm{kJ} / \mathrm{kg}$ (IRSC) at the same time and solar radiation. For same radiation intensity, the result from calculation at ETSC is higher than experimental result because this calculation uses several assumptions, solar collector operated at new condition, water properties is pure, the properties of solar collector's parts are uniform and constant at specific time. At Figure 10.b, if inlet temperature of working fluid is increased, outlet temperature is also increase if only temperature of absorber pipes is higher than inlet temperature of water. If inlet temperature increases, the difference of inlet and outlet temperature is decrease because the convective heat transfer coefficient of water inside collector pipe is also increase. The difference temperature between inlet and outlet temperature of water become decrease.

Compared with FPSC, CPSC has better performance because reflector plate with compound parabolic profile can reflect radiation to absorber pipes, so that the total absorbed heat at IRSC is higher than FPSC. For application on ejector 
refrigeration cycle, the better solar collector is evacuated tubes because of absorbed heat by working fluid is highest compared to the others. The higher outlet temperature of water at solar collector side, the higher amount of heat can be transferred to refrigerant and outlet temperature of refrigerant will higher. The entrainment ratio is higher if outlet temperature of refrigerant higher. The entrainment ratio is defined as mass flow rate at evaporator side divided mass flow rate at a generator side. The higher entrainment ratio cause higher mass flow rate at evaporator side and the cooling capacity or cycle efficiency is increase.

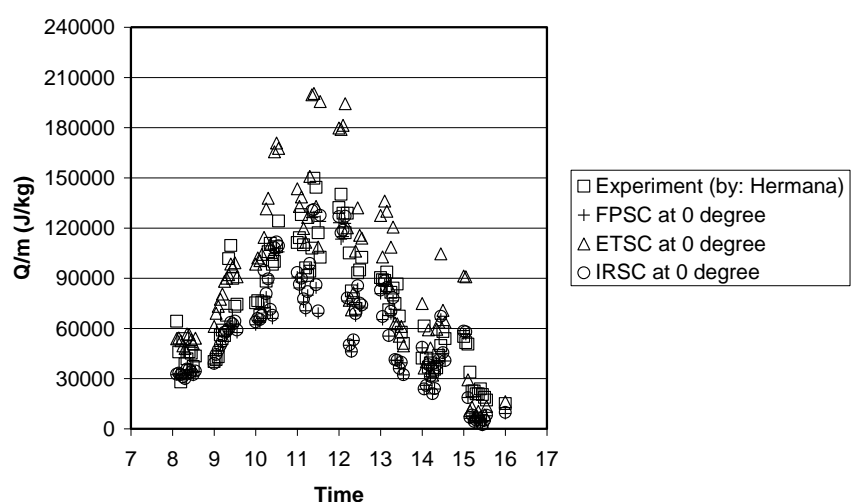

(a) Characteristics of absorbed heat by working fluid at 0 inclination of solar collector.

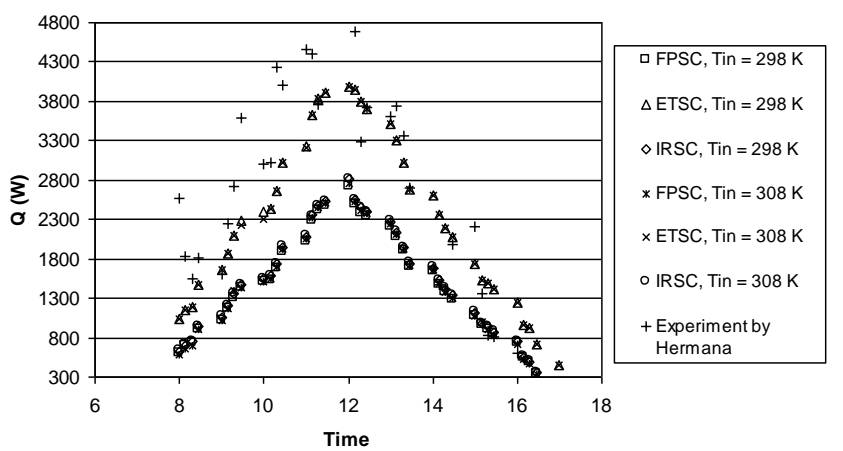

(b) Characteristics of absorbed heat by working fluid at different inlet temperature of working fluid.

Figure 10 Comparison of calculation result with another experiment.

\section{Conclusion}

The calculation method of heat transfer analysis in this study can predict and compare performance of three types of solar collectors such as configuration of absorbed heat by collectors, heat loss, thermal efficiency, cover and bottom 
plate temperature, and outlet temperature of water at four inclination positions of the solar collectors. The best inclination position of the solar collector is 0 degree. Using evacuated tubes solar collector, the maximum heat which can be absorbed by solar collector is $3991.91 \mathrm{~W}$ with aperture area $3.5 \mathrm{~m}^{2}$ and assumption that the maximum radiation intensity occurs at 12.00 with intensity $970 \mathrm{~W} / \mathrm{m}^{2}$. The highest outlet temperature of water is $347.15 \mathrm{~K}$ with mass flow rate $0.02 \mathrm{~kg} / \mathrm{s}$. Configuration of this calculation result indicates the same tendency with another experimental result [10] although there is a small deviation compared to the experiment result. The biggest heat loss comes from cover plate in order to get the better performance, cover plate should be added (with double cover plate). From calculation result, the highest heat loss occurs on IRSC, $995.472 \mathrm{~W}$ and the lowest heat loss occurs on ETSC, $243.916 \mathrm{~W}$, at 12.00 with the highest solar intensity.

\section{Nomenclature}

$\begin{array}{lll}A_{c} & \text { collector area } & \left(\mathrm{m}^{2}\right) \\ D_{i} & \text { inner diameter } & (\mathrm{m}) \\ D_{o} & \text { outer diameter } & (\mathrm{m}) \\ h & \text { convention heat transfer coefficient } & \left(\mathrm{J} \cdot \mathrm{kg}^{-1}\right) \\ \dot{m} & \text { mass flow rate } & \left(\mathrm{kg} \cdot \mathrm{s}^{-1}\right) \\ P & \text { pressure } & (\mathrm{Pa}) \\ Q_{f} & \text { heat rate of working fluid } & (\mathrm{W}) \\ R & \text { thermal resistance } & \left(\mathrm{m}^{2} \cdot \mathrm{K}^{-} \mathrm{W}^{-1}\right) \\ T & \text { temperature } & (\mathrm{K}) \\ \mathrm{U} & \text { overall heat transfer } & \left(\mathrm{m}^{2} \cdot \mathrm{K}^{-1} \mathrm{~W}^{-1}\right) \\ & \text { coefficient } & \end{array}$

Greek letters

$\begin{array}{lll}\rho & \text { reflectivity } & (-) \\ \eta & \text { thermal efficiency } & (\%) \\ \tau & \text { transmissivity } & (-) \\ \eta & \text { efficiency } & (\%) \\ \alpha & \text { absorptivity } & (-) \\ \phi & \text { declivity } & (\mathrm{deg}) \\ \mu & \text { viscosity } & (\mathrm{Pa} \cdot \mathrm{s})\end{array}$

\section{Subscripts}

a ambient

$b \quad$ insulation plate

$c \quad$ cover plate

$f \quad$ working fluid 
$\begin{array}{ll}i & \text { inlet } \\ o & \text { outlet } \\ p & \text { absorber } \\ r & \text { reflector }\end{array}$

Abbreviations

CPSC compound parabolic solar collector

IRSC involute reflector solar collector

FPSC flat plate solar collector

ETSC evacuated tube solar collector

\section{References}

[1] Chan, S., Sato, H., Suwono, A., Astina, I M., \& Darmanto, P. S., Ejectorbased Refrigeration Cycle Using HCs as the Working Fluid, 8th IIR Gustav Lorentzen Conference on Natural Working Fluids, Copenhagen, 2008.

[2] Pridasawas, W., Solar-Driven Refrigeration Systems with Focus on the Ejector Cycle, Doctoral Thesis, Royal Institute of Technology KTH, Stockholm, 2006.

[3] Pilatowsky, I., Rivera, W., \& Romero, J. R., Performance Evaluation of a Monomethylamine-Water Solar Absorption Refrigeration System for Milk Cooling Purposes, Applied Thermal Engineering, 24(7), 1103-1115, 2004.

[4] Koo, J. M., Development of a Flat Plate Solar Collector Design Program, Master Thesis, Wisconsin University, USA, 1999.

[5] Riffat, S. B., Doherty, P. S., \& Abdel, A. E. I., Performance testing of different types of liquid flat plate collectors, Int. Journal of Energy Research, 24, Nottingham University, UK, 2000.

[6] Riffart, S. B., Zhao, X., \& Doherty, P. S., Developing a Theoretical Model to Investigate Thermal Performance of a Thin Membrane HeatPipe Solar Collector, Applied Thermal Engineering, 25, 899-915, 2005.

[7] Duffie, J. A \& Beckman, W. A., Solar Engineering of Thermal Processes, 2nd Edition, John Wiley \& Sons, New York, 1991.

[8] Lemmon, E. W., Jacobsen, R. T., Penoncello, S. G., \& Friend, D. G., Thermodynamic Properties of Air and Mixtures of Nitrogen, Argon, and Oxygen From 60 to $2000 \mathrm{~K}$ at Pressures to $2000 \mathrm{MPa}$, Physical Chemical Ref. Data, 29(3), 331-362, 2000.

[9] Lemmon, E. W., Huber, M.L., \& McLinden, M. O., Thermodynamic and Transport Properties of Refrigerants and Refrigerant mixture (REFPROP), NIST Standard Reference Database 23 Ver. 8.0, 2007. 
[10] Ierardi, J. A., A Computer Model of Fire Spread from Engine to Passenger Compartments in Post-Collision Vehicles, Master thesis, Worcester Polytechnic Institute, 1999.

[11] Agus Hermana, Pengembangan Metode Simulasi untuk Perancangan dan Prediksi Performansi Sistem Pengkondisian Udara Energi Surya, Doctoral Dissertation, Institut Teknologi Bandung, 2006.

[12] Selvaraju, A. \& Mani, A., Analysis of an Ejector with Environment Friendly Refrigerants, Applied Thermal Engineering, 24, 827-838, 2004.

[13] Summers, D. A., Thermal Simulation and Economic Assessment of Unglazed Transpired Collector Systems, Master Thesis, Wisconsin University, USA, 1995.

[14] Khalifa, A. M. A., Taha, M. M. A., \& Akyurt, M., Design, Simulation, and Testing of a New Concentrating Type Solar Cooker, Solar Energy, 38(2), 79-88, 1987.

[15] Souka, F. A. \& Safwat, H. H., Optimum Orientations for the Double Exposure Flat-Plate Collector and Its Reflector, Solar Energy, 10(4), 170-174, 1966.

[16] Harding, G. L. \& Zhiqiang, Y., Thermosyphon Circulating In Solar Water Heaters Incorporating Evacuated Tubular Collectors and a Novel Water-In-Glass Manifold, Solar Energy, 34(1), 13-18, 1985.

[17] Mertens, H. \& Polman, A., Depth-Resolved Nanostructure and Refractive Index of Borosilicate Glass Doped with Ag Nanocrystals, Optical Materials, 29, 326-331, 2006.

[18] Zhang, J. X. \& Wang, Z. R., A New Combined Adsorption-Ejector Refrigeration and Heating Hybrid System Powered by Solar Energy, Applied Thermal Engineering, 22(11), 1245-1258, 2002.

[19] Hollands, K. G. T., Unny, T. E., Raithby, G. D., \& Lonicek, L., Free Convection Heat Transfer Across Inclined Air Layers, Transactions of ASME Journal of Heat Transfer, 98, 189-201, 1976.

[20] Lunde, P. J., Solar Thermal Engineering, Space Heating and Hot Water Systems, John Wiley \& Sons, New York, 1980.

[21] Soin, R. S., Raghuraman, S., \& Murali, V., Two-Phase Water Heater: Model and Long Term Performance, Solar Energy, 38(2), 105-112, 1987.

[22] Yiqin, Y., Hollands, K. G. T., \& Brunger, A. P., Measured Top Heat Loss Coefficients for Flat Plate Collectors with Inner Teflon Covers, Proceedings of the Biennial Congress of the International Solar Energy Society, Denver, Colorado, USA, August 19-23, 1200-1210, 1991. 